\title{
Tempo, Sofrimento e Ímpeto Vital: Investigações Fenomenológicas em Minkowski
}

\author{
Franciane Indianara Nolasco* (1) \& Joanneliese de Lucas Freitas (1) \\ Universidade Federal do Paraná, Curitiba, PR, Brasil
}

\begin{abstract}
RESUMO - O objetivo do presente trabalho é apresentar como se relacionam os conceitos de tempo, sofrimento e ímpeto vital em Minkowski, a partir de seu modo de aparição no trabalho Estudo psicológico e análise fenomenológica de um caso de melancolia esquizofrênica. Tal escolha se deu pela importância histórica da obra que introduziu seu pensamento nas Américas. A seguir, apresenta-se esta íntima ligação conceitual em textos do psiquiatra, datados posteriormente a este primeiro, em que tais temas são desenvolvidos e aprofundados. Conclui-se que mesmo que tal relação temática não tenha sido realizada de modo explícito, ao recorrer ao estudo de um destes três conceitos, os outros dois aparecem como indispensáveis no escopo teórico de seus estudos, a partir de suas relações intrínsecas, constitutivas da existência humana.
\end{abstract}

PALAVRAS-CHAVE: Minkowski, tempo, sofrimento, ímpeto vital

\section{Time, Suffering and Vital Impetus: Phenomenological Investigations in Minkowski}

\begin{abstract}
The aim of this paper is to present the way Minkowski relates the concepts of time, suffering and vital impetus since its appearance in the text Findings in a case of schizophrenic depression. This choice was made due to the historical importance of this work that introduced Minkowski's ideas in the Americas. It is, then, presented how the intimate connection of these three concepts appears in later texts in which such themes are developed and deepened. In conclusion, when Minkowski reflects theoretically on one of these three concepts, even when such a thematic relationship is not explained, the other two concepts appear as essential in its theoretical scope, due to their intrinsic and constitutive relations in human existence.
\end{abstract}

KEYWORDS: Minkowski, time, suffering, vital impetus

Éugene Minkowski ao lado de Karl Jaspers, Ludwig Binswanger, Medard Boss, Hubertus Tellenbach e Arthur Tatossian, foi um psiquiatra da tradição da psicopatologia fenomenológica, sendo um dos primeiros a repensar sua terapêutica de forma crítica à psiquiatria tradicional. Segundo Bloc et al. (2016), a tradição da psicopatologia fenomenológica é formada por psiquiatras que se apropriaram da filosofia de Edmund Husserl e Martin Heidegger para tal tarefa. A noção de fenômeno na filosofia fenomenológica constitui, particularmente, base epistemológica de uma nova compreensão da existência humana dentro do âmbito dessa apropriação.

Em contrapartida ao método da apreensão do doente via diagnóstico de um quadro sintomático, há um esforço em retornar ao fenômeno clínico em seu movimento mais originário de mostração, bem como ao sentido daquilo que se apresenta a quem se apresenta, em outras palavras, da experiência vivida por esse outro sobre quem o clínico se debruça. É uma abordagem que marca uma suspensão dos contrastes entre saúde e doença, normal e patológico e corresponde a um ponto de criação de conhecimento do qual muitas críticas podem ser deslindadas (Bloc et al., 2016; Souza et al., 2020). Críticas tanto ao modo como se produz conhecimento nas ciências humanas, quanto às abordagens clínicas psiquiátricas e psicológicas tradicionais, advindas, sobretudo, de uma nova compreensão acerca do que seja o humano e a existência. Para Minkowski, esse campo de estudo do ser humano é antes, campo do patológico,

\footnotetext{
*E-mail: francianeinolasco@gmail.com

- Submetido: 04/08/2016; Aceito: 12/01/2021.
} 
do pathos, do sofrimento em seu caráter existencial. Em outras palavras, o psiquiatra passou a pensar a patologia não apenas por seu caráter limitadamente mórbido, mas como um modo de ser da existência. Esse modo de aproximação ao fenômeno psicopatológico fez com que Minkowski nos deixasse de herança estudos sobre o tempo vivido, sobre a melancolia esquizofrênica, a espacialidade e ainda um tratado de psicopatologia.

O psiquiatra foi o primeiro a discutir o tempo vivido como eixo primordial para a compreensão da depressão, bem como da psicopatologia em geral. Tal contribuição abriu caminho para que outros médicos buscassem aprofundamento nos fenômenos psicopatológicos em suas condições de possibilidades no solo da existência, tal como Binswanger, Tellenbach e Tatossian (Souza \& Moreira, 2018). Com essa nova perspectiva sobre o caráter pathico da existência, Minkowski passa a compreender a clínica como um fazer que deve integrar esse novo modo de ser que se apresenta à teoria e ao saber da profissão e não o oposto, ou seja, como uma prática que encerra o que se apresenta clinicamente em postulados teóricos dados de antemão (Barthélémy, 2015).

Os temas do tempo vivido e do sofrimento se encontram presentes na obra de Minkowski, mas são explorados de uma forma peculiar e singular em um estudo de caso conhecido como Étude et analyse psychologique phénoménologique d'un cas mélancolie schizophrénique. Nesse estudo, nota-se particularmente a problemática do tempo e do sofrimento vinculada ao que o autor nomeia de ímpeto vital, sempre consoante com sua perspectiva de elucidar a clínica e a teoria a partir do que se apresenta como vivido e não o oposto. $\mathrm{O}$ enlace entre tais temas pode parecer acidental em um primeiro momento. No entanto, desvela-se recorrente no bojo das reflexões posteriores do psiquiatra, ganhando um status de constituição para o qual este artigo pretende chamar atenção: a tese de que as três temáticas, tempo, sofrimento e ímpeto vital, aparecem frequentemente unidas nas discussões de Minkowski e - por se tratarem de facetas do mesmo fenômeno, a existência, devem ser compreendidas em relação. O objetivo do presente trabalho aqui se delineia, pois, como sendo o de descrever esta relação entre as temáticas tempo, sofrimento e ímpeto vital, entendida como central para a compreensão da obra do autor. Para tanto, é apresentado em um primeiro momento um estudo minucioso do seu modo de aparição no estudo de caso acima citado, na sequência e ordem de desenvolvimento apresentados pelo próprio autor, para, em seguida, apresentá-las em seus textos posteriores. Anteriormente a essa reflexão, contudo, iniciaremos o trabalho com uma breve contextualização do inovador pensamento do psicopatólogo.

\section{PIONEIRO DA PSICOPATOLOGIA FENOMENOLÓGICA}

Eugène Minkowski, um dos pioneiros dentre os proponentes da psicopatologia fenomenológica, foi um médico russo, nascido no século XIX, responsável pela disseminação dos estudos fenomenológicos no campo da psicopatologia (Bloc et al., 2016; Souza et al., 2020). Refugiado durante a Primeira Guerra Mundial, teve contato com Bleuer e a psicanálise, encontrando nesta experiência conflitos de ordem ética com relação à teoria freudiana da sexualidade. Estudioso da medicina e da filosofia, desde os tempos de sua graduação, foi na fenomenologia de Husserl e Heidegger, na filosofia de Bergson e, principalmente, na obra de Binswanger (com quem também conviveu) que encontrou as bases teóricas para o desenvolvimento de seu pensar singular e de seu trabalho no âmbito da psicopatologia (Abreu e Silva Neto, 2004). Para tanto, afastou-se das concepções biologicistas, mecanicistas e causalistas do homem e desenvolveu

uma abordagem rigorosa e radical do método fenomenológico existencial; rigorosa no sentido de Husserl e radical enquanto proposta de realização do abandono do pensamento geométrico da ciência em favor de uma perspectiva alternativa e complementar que trata do caráter expressivo e de significação dos fatos; ou seja, o desenvolvimento de um método que não tenha em vista determinar leis causais ou a gênese dos fatos da psicopatologia mas sim que procure descrever-lhes o caráter expressivo e compreender-lhes o significado. (Abreu e Silva Neto, 2004, p. 60)
Minkowski (2000) compreende que o campo da psicopatologia é, por excelência, o campo de estudo da existência humana, visto que, a patologia a que comumente se refere a tradição é um aspecto mórbido daquilo que é do caráter humano. Usa-se agora "humano" em detrimento do termo "normal", assim como "mórbido" no lugar de "transtorno". Se a psicopatologia é um aspecto mórbido da existência humana, é essa que deve ser estudada para que aquela seja compreendida.

Minkowski (2016) interessa-se, portanto, muito mais por uma psicologia da patologia do que por uma patologia da psicologia. Enquanto essa se refere à patologia como uma área da psicologia e que teria por escopo a análise dos limites entre o normal e o patológico, aquela se refere muito mais à possibilidade de compreender que há uma ordem própria intrínseca ao fenômeno da "loucura", a qual é possível irmos ao encontro, reapreendendo a experiência do paciente em seu lugar mais próprio, o de sua existência. Minkowski também compreende que tal lugar de existência, o dito "patológico", não se encontra assim tão apartado do que seja uma realidade "normal", contendo muitos pontos em comum e principalmente com possibilidades de diálogo entre si. Segundo Bloc et al. (2016), essa é uma das grandes contribuições de Minkowski para o campo da psicopatologia, a saber, a redefinição de sua tarefa e de seu significado. A psicopatologia passa a ser entendida não mais como a ciência que define a doença e sua 
associação com o conceito de saúde, mas a um movimento de compreensão do fenômeno fundamental da existência humana e esse novo modo de ser que se apresenta, antes compreendido de antemão apenas como um ser adoecido (Bloc et al., 2016).

Tal tarefa não é uma simples ressignificação de conceitos, mas antes um repensar profundo e crítico sobre o papel do olhar do profissional ao fenômeno que se apresenta em sua clínica, bem como daquilo que compreende como tratamento. Para Barthélémy (2015), Minkowski buscou questionar a multiplicidade das técnicas dentro do âmbito psiquiátrico de sua época. A pura utilização da técnica sem reflexão sobre seu fundo e seu valor no conjunto da psicoterapia é, até os dias atuais, uma reflexão necessária. Nesse afastamento do olhar do quadro sintomático em direção ao paciente e, portanto, afastamento também de uma postura de suposta autoridade de saber do médico ou psicólogo, Minkowski funda, segundo Barthélémy (2015), o método fenômeno-estrutural. Nesse seu repensar, compreendeu que é de responsabilidade ética e do exercício da profissão um permanente corrigir a trajetória do processo terapêutico à medida que o paciente delega ao profissional a tarefa de compreensão e esclarecimento de sua situação. Era comum seus pacientes chegarem à terapia desamparados por estigmatizações advindas de diagnósticos, buscando sempre explicações dadas pelo médico que lhes oferecem esclarecimento sobre seu estado. Para Barthélémy (2015), Minkowski caminha em direção a uma terapia que não empobreça a experiência do doente por tentar reduzi-lo ao curso de seu diagnóstico ou a uma dada terapêutica, mas sim a compreender como este (diagnóstico) se impõe a essa dada existência.

\section{MINKOWSKI NO BRASIL E AO REDOR DO MUNDO}

Os escritos de Minkowski no Brasil têm caminhado a passos lentos, em suas apropriações e no conhecimento de suas ideias (Bazzo, 2019). Abreu e Silva Neto (2004) nos ofereceu um panorama de como isso vinha acontecendo até o ano de 2004, data de sua revisão. Além de muitas investigações sobre o Método de Rorschach, Abreu e Silva Neto datou os seguintes trabalhos: dois sobre o sofrimento na perspectiva de Minkowski, três estudos baseados na obra Le temps vècu (O tempo vivido, 1933), que discutem as contribuições posteriores para os campos da psicoterapia, para as investigações sobre os modos de subjetivação e sobre a Educação Matemática; e, por fim, uma pesquisa sobre a saúde existencial, que teve seu método de estudo fundamentado na perspectiva de Minkowski, além de suas próprias publicações que consistem em apresentações das obras do psiquiatra (Abreu e Silva Neto, 2004). A partir de 2004, encontra-se publicado o estudo de Costa e Medeiros (2009) que retoma a questão do tempo em Santo Agostinho e em Bergson, mostrando seus deslindes para o pensamento de Minkowski e ressaltando sua importância para se pensar o tempo na clínica fenomenológica. Sobre a importância de Minkowski para o atendimento terapêutico encontram-se os estudos de Antúnez e Faizibaioff (2014), Antúnez et al., (2014) e a publicação da conferência de Barthélémy (2015). Diante desse panorama, os estudos sobre a obra do psiquiatra mantêm-se atuais, principalmente no campo dos estudos fenomenológicos, dada sua escassez (Abreu e Silva Neto, 2004). De cinco anos para cá, houve um crescimento das publicações que fazem referência ao trabalho do psiquiatra, inclusive traduções de textos seus e apresentações na recente revista Psicopatologia Fenomenológica Contemporânea.

Segundo Bazzo (2019), em 1997, aproximadamente 75 anos após a apresentação do primeiro texto de Minkowski, o acesso e apropriação de seus estudos e ideias originais neles apresentadas ainda eram precários. Apesar da divulgação de seu pensamento ter aumentado no cenário da França a partir dos anos 90, no Brasil apenas nos últimos 10 anos é que se percebe um aumento de sua divulgação em importantes revistas nacionais (Bazzo, 2019). Internacionalmente, são poucos os estudos encontrados que datam dos últimos anos. Seus estudos são citados em uma pesquisa sobre o papel da intersubjetividade na experiência esquizofrênica (Pienkos, 2015) e são retomados de forma mais aprofundada, principalmente sua noção de tempo vivido em um estudo sobre a temporalidade na psicose (Denischik, 2015). Segundo Urfer (2001), os estudos de Minkowski vêm sendo cada vez mais reconhecidos no cenário Anglo-Saxão, graças às traduções totais ou parciais de suas obras. Já na França, segundo o autor, são constantes os movimentos de reedição e reimpressão das obras do psicopatólogo (Urfer, 2001).

As recentes apropriações de seus estudos se devem em parte pelo seu pioneirismo e por suas contribuições na tentativa de lançar mão do método fenomenológico para se aproximar do fenômeno da psicopatologia. Seu consequente afastamento da perspectiva biologicista, mecanicista e causalista de tal fenômeno integra implicações teóricas e práticas que permitem até os dias atuais um acesso ao fenômeno da clínica por uma via muito próxima de seu caráter vivido e existencial. Souza e Moreira (2018), em um estudo sobre a depressividade, discutem como Minkowski foi essencialmente pioneiro ao compreender a depressão a partir da aproximação à experiência vivida do paciente clínico. Marmorato (2012) também encontrou nos estudos sobre o tempo vivido uma fonte muito importante para compreensão da relação fundamental entre tempo e atividade na existência, em especial para pensar o fenômeno da hiperatividade enquanto possibilidade existente para todo ser humano para aquém de seu caráter psicopatológico.

A partir do livro Existence, organizado por Henri F. Ellenberger e Rollo May, o pensamento de Minkowski e de outros importantes fenomenólogos europeus, difundiu-se nas Américas desde 1958 (Abreu e Silva Neto, 2004; Feijoo \& 
Mattar, 2016). Nos anos 60 foi traduzido para o espanhol, se tornando acessível para toda a América Latina, exceto para o Brasil, pois nunca ${ }^{1}$ ganhou uma tradução em português. Nesse livro, com dedicatória à Minkowski e Binswanger, é publicado um famoso estudo de caso de Minkowski que ganha na tradução espanhola o título Hallazgos en un caso de depresión esquizofrênica, versão utilizada no presente artigo.
Esta obra é considerada a primeira compreensão de um caso clínico pela aplicação do método fenomenológico (Bazzo, 2019) e junto a Sur la Phénoménologie de Binswanger, presente no livro Introduction à l'analyse existentielle, é considerada ponto de partida para o surgimento da psicopatologia fenomenológica (Bazzo, 2019; Bloc et al., 2016).

\section{O TEXTO ESTUDO E ANÁLISE FENOMENOLÓGICA DE UM CASO DE MELANCOLIA ESQUIZOFRÊNICA}

O estudo de caso em Étude et analyse psychologique phénoménologique d'un cas mélancolie schizophrénique foi originalmente apresentado na $63^{\text {a }}$ Jornada Científica da Sociedade Suíça de Psiquiatria, no ano de 1922. Posteriormente foi retomado nos estudos do psiquiatra sendo considerado por ele um exemplo de análise fenomenológicaestrutural ainda 40 anos depois de seu primeiro aparecimento em 1922 (Bazzo, 2019).

$\mathrm{Na}$ leitura desse texto é notório o desvelar de uma interpretação fenomenológica sobre o caso de um paciente psicopatológico acompanhado pelo psiquiatra. Mais que isso, o trabalho que Minkowski (1967) nos apresenta é como acompanhar o fazer do artista no desvelar de sua pintura. Cada pensamento que antecipa a pincelada do objeto descrito pode ser acompanhado em seu nascimento revelando-nos não apenas o objeto pintado como também o sujeito pintor. É como se ele não se detivesse apenas à descrição de sua experiência enquanto médico de seu paciente, mas como se nos permitisse acessar os bastidores de sua alma, no processo de encontro com a pessoa que é seu paciente, antes de sua definição como um quadro clínico. Revelando-nos uma prática muito mais próxima da vida em seu pulsar originário e uma utilização do saber teórico em função de sua expressão do que de seu encerramento. Deste encontro entre ambos, o médico faz surgir em seu texto uma descrição puramente fenomenológica em seu caráter clínico, uma vez que este passo dado nas profundezas da existência do paciente com quem conviveu durante dois meses, permitiu-lhe uma vivência única do fenômeno que ali se lhe apresentava.

Um passo aquém, anterior ao do diagnóstico tradicional médico foi dado, com o intuito de conhecer o paciente como existência, como força de vida. Após este passo, Minkowski (1967) debruça-se novamente sobre o diagnóstico e o eleva a um patamar diferenciado, pertencente àquilo que compreendia como psicopatologia, como psicologia do pathos. Em seu texto, um tópico é inteiramente dedicado às descobertas fenomenológicas por ele realizadas nesta caminhada, desvelando esta descrição "diagnóstica" diferenciada do caso em si e, por consequência, desse processo de encontro com a existência, desvelando também os movimentos do existir humano. Neste tópico, Minkowski (1967) descreve suas descobertas circundando duas temáticas centrais de análise, a saber, tempo e sofrimento. No entanto, uma terceira temática, ímpeto vital, aparece nas entrelinhas de sua interpretação e mostra-se necessária para o tratamento da questão do tempo e do sofrimento. A seguir, faremos a apresentação das reflexões do psiquiatra ao longo da apresentação do caso, buscando cumprir a demonstração da relação entre os temas da temporalidade, sofrimento e ímpeto vital.

\section{A APRESENTAÇÃO DO CASO EM UMA PRIMEIRA CAMADA SIMPLIFICADA E OBJETIVA}

Inicialmente, Minkowski (1967) delineia a qualidade de sua estadia ao lado de seu paciente. Permanecera a seu lado durante todos os dias dos meses seguidos, tempo que lhe trouxe uma experiência com o paciente em seu ambiente natural (fora de instituições psiquiátricas). Em seu diagnóstico psiquiátrico tradicional, tratava-se de um caso de psicose depressiva de mania persecutória e de interpretações extensivas. Para o psiquiatra, em sua descrição do fenômeno ali desvelado, a razão deste diagnóstico se deu pelo fato de

1 Ressalvamos que recentemente (2019), apenas o texto Hallazgosenun caso de depresión esquizofrênica especificamente ganhou sua primeira tradução para o português. que se tratava de um sujeito que apresentava ideias de culpa e de destruição diante da certeza de que havia cometido crimes terríveis, como ser estrangeiro e não ter escolhido a cidadania francesa, razão pela qual tinha a mais absoluta certeza de que receberia castigos cruéis (juntamente com seus familiares, embora o foco da descrição fosse sempre ele mesmo) a serem aplicados pelas pessoas ao seu redor, que eram na verdade, espiões e traidores que o vigiavam, visto que todos estavam inteirados de seus crimes.

Além dessas ideias, o paciente apresentava uma singular interpretação que chamava de "política de desperdícios". Ela consistia em um sistema político instituído contra ele em que todos os desperdícios, absolutamente tudo 
que fosse descartável e residual no mundo, lhe seriam introduzidos nos intestinos. Minkowski (1967) se detém, então, em esmiuçar em pormenores os detritos que mais preocupavam seu paciente dentro dessa política. Assim o fazia, na verdade, seu paciente: enumerava e interpretava em cadeias de pensamentos intermináveis os detritos que lhe seriam introduzidos nos intestinos. Nas palavras do médico, o paciente tendia a um trabalho intelectual diante dos objetos do mundo (que já sempre faziam parte desta política). À lista destes acrescentava absolutamente tudo que pudesse lembrar ou imaginar em meio a sua cadeia de pensamentos infinita. De modo que todas as coisas existentes no mundo acabavam por fazer parte deste sistema e eram imediatamente recebidas pelo paciente de modo hostil.

A princípio, compreende o médico, trata-se de mais uma pessoa com doença mental e nada novo nos traria uma reflexão mais apurada sobre o caso. Seria uma repetição estudar um caso tão comum e universal dentro da psicopatologia. No entanto, para Minkowski (1967) trata-se de um caso muito vantajoso para quem deseja penetrar na verdadeira natureza do fenômeno psicopatológico. Nesse momento, abre-se a primeira reflexão na escritura acerca de seu trabalho e as diferenças deste para com o trabalho dos médicos de sua época. A partir do olhar fenomenológico, passa a buscar não mais uma metodologia que busque as expressões do paciente como sintomas, mas cumpre a tarefa de suspender o conhecimento pré-concebido do diagnóstico e lança ao paciente um olhar que busca compreender sua expressão na unicidade e especificidade do seu ser. Para tanto, recusa a possibilidade de perguntar sobre o conteúdo das manias e alucinações e adentrar na apreensão diagnóstica na qual a psiquiatria moderna se instrumentaliza, a saber, os jogos de fatores afetivos, os complexos e os simbolismos. Diferentemente, acredita que o melhor caminho é o compreender a mania em si mesma, como fenômeno único e específico que precisa ser acompanhado lado a lado em sua emergência. Esse lado a lado foi possível enquanto teve a oportunidade de observar diariamente o aflorar mais nítido das reações de seu paciente aos estímulos externos, de seu ambiente natural. Presenciando assim, sua variabilidade de sintomas, seu poder de adaptação e seus matizes particulares. Tal estada assim tão próxima, nos revela Minkowski (1967), trouxe-lhe à tona seu caráter pessoal para além do profissional, como não podia deixar de ser. E isto fez com que a todo tempo pudesse comparar sua psique à do paciente e, adentrando nesta com tamanha profundidade, a ponto de realizar descobertas notáveis de cunho psicológico e fenomenológico. Utiliza-se da metáfora da harmonia musical para explicar esse fenômeno ao qual chama de simbiose ${ }^{2}$. Como se duas linhas melódicas antes tocadas separadamente tivessem a oportunidade de realizar contrapontos, interações de encontros e desencontros, perguntas e respostas que ora faz figurar uma linha, ora outra a partir do seu coexistir.

\section{APRESENTAÇÃO DAS DESCOBERTAS PSICOLÓGICAS QUE REALIZOU NESSE ENCONTRO}

É interessante notar que Minkowski (1967) realiza uma transição no modo de apresentação a partir destas linhas. É como se saísse do caráter objetivo e descritivo para alcançar um caráter interpretativo, já com viés de relato de experiência vivida enquanto médico pessoal. Mesmo assim, ainda faz surgir alguns elementos de descrição aos quais não havia se remetido anteriormente. Minkowski (1967) nos detalha como o paciente dentro de seu sintoma apresentava variações de acordo com as circunstâncias, respondendo sempre a motivos precisos. O médico pôde distinguir duas atitudes recorrentes dentre tais variações: o predomínio dos elementos depressivos e, outrora, dos elementos maníacos e delirantes. Ele nos chama atenção para a existência de um modo de contato do paciente com os outros e adentra sua primeira interpretação acerca do caso: acontecia que o caráter depressivo se manifestava particularmente depois de brigas violentas, especialmente no momento em que o médico se dirigia àquele com pedido de paz. Logo o paciente se derramava em uma lamentação melancólica, de autocompadecimento, enumeração de desgraças, pedidos de compaixão e gritos de dor, que aos poucos iam deixando de comovê-lo e que, no entanto, persistiam como seu modo de relação com seu médico na simbiose em que se encontravam. O segundo comportamento percebido era que o paciente o tratava ora como um amigo muito prezado, ora como mais um dos conspiradores do mundo. E assim, nessa flutuabilidade de atitudes, iam se desvelando em um vai e vem entre sua "vida normal" e a "psique patológica".

Dentre todos estes comportamentos descritos, houve um em particular no qual Minkowski (1967) se demorara, e que chamou de "sopro de vida" entre as sombras da personalidade enferma de seu paciente. Acontecia de modo que bastava uma surpresa com um objeto que havia "esquecido" de colocar na lista da política dos desperdícios para que iniciasse uma cadeia de lembranças de outros objetos da mesma categoria que lembrasse ou que pudesse imaginar e criar. E assim se ocupava por dias, naquela tarefa de recordação infinita, como a descrevia o próprio paciente. Dentro deste movimento, era comum nomear o que estava ao seu redor, classificando tudo dentro de uma

2 É importante compreender que o termo simbiose utilizado por Minkowski (1967) possui bases epistemológicas na noção de intersubjetividade da fenomenologia e não se refere ao termo psicanalítico. A sua compreensão será aprofundada ao longo do texto. 
mesma ordem geral, todos com o mesmo fim. Também se detinha sobre algumas preocupações como, por exemplo, os enormes gastos de tal política ou como poderiam colocar-lhe nos intestinos as sombrinhas e as bengalas de caminhar. Sempre encontrava alternativas para que o procedimento fosse bem-sucedido (Minkowski, 1967).

\section{DESVELAMENTO DAS DESCOBERTAS FENOMENOLÓGICAS A RESPEITO DO CASO DE SEU PACIENTE}

Esse campo de reflexão é-nos aberto pela seguinte questão: "Em que está a discrepante diferença entre sua psiqué e a nossa?" (Minkowski, 1967, p. 168). Tal pergunta guiará os passos do autor por novos caminhos dentro do campo de estudos da psicopatologia traçados no texto seguido. $\mathrm{O}$ autor retoma a necessidade de afastamento da interpretação psiquiátrica vigente em sua época, que recorria aos complexos e simbolismos, assumindo a postura fenomenológica que se interessa pelas perguntas: "O que é a mania? ... é nada mais que um transtorno de percepção e juízo?" (Minkowski, 1967, p. 168).

Em busca das respostas, retorna ao fenômeno e retoma a rotina com seu paciente. Surge-lhe um fenômeno de interpretação expresso nos sintomas: o aspecto temporal da existência do paciente. Aí, Minkowski (1967) encontra o solo para o desvelar da existência em si mesma. Relata-nos que, todos os dias, o paciente tinha absoluta certeza de que era seu dia do juízo final, eram o dia e a noite quando a manhã seguinte não chegaria sem que as penas fossem aplicadas. Toda atmosfera de medo e vigília de tais pensamentos muitas vezes deslindaram em noites mal dormidas. No começo, o médico tinha expectativa de que na vinda da manhã seguinte, o paciente se defrontasse com o fato de que nada havia ocorrido e pudesse pôr fim a essa ideia. Perdeu as esperanças quando os dias se passavam e a experiência se repetia. O que há de particular nisto? Minkowski compreende que, como ser humano, ele conseguia basear-se nos fatos observados para tirar conclusões sobre o futuro. Já seu paciente, em seu aspecto mórbido, mostrou-se incapaz de realizar tal raciocínio, repetindo todos os dias a mesma jura sem prestar atenção alguma em possíveis relações entre seu passado e seu presente. Havia perdido a habilidade de planejar seu futuro com base nos fatos que se dão, como o fazem assim os seres humanos práticos que somos. A marcha desde o presente e do passado para o futuro parecia totalmente ausente em seu paciente. Não mostrava tendência de generalizar nem de chegar a uma norma empírica. Até mesmo diante dos questionamentos de seu médico sobre os fatos empíricos que presenciava - de os dias se passarem sem que as punições fossem aplicadas - argumentava claramente que nada disso garantia seu amanhã. O futuro, afirma Minkowski (1967), que para nós está em uma progressão, para ele parecia mais como um fragmento solto.

Pode-se dizer que essa vivência particular do tempo é consequente natural do quadro clínico da mania? Aparentemente, diz Minkowski (1967), é possível, mas é equivocada à medida que não se atenta para o que o autor vem então nos revelar: o transtorno fundamental é a própria atitude equivocada diante do futuro, do qual a mania é apenas uma de suas expressões. Ao retomar o caso, o psiquiatra explica: seu paciente sabia que o tempo transcorria, ele passa para ele com uma uniforme monotonia. Tudo que lhe unia ao mundo era o fato de que os objetos aumentavam o acervo de desperdícios a serem usados contra ele. Não havia de sua parte nenhuma ação nem desejo do presente que se estendesse para o futuro. O resultado eram dias conservados de uma independência insólita ao não se englobar em uma percepção de vida continuada. Cada dia começava novamente, e o que havia feito e falado não tinha o mesmo valor que na vida de um homem sem a psicopatologia, visto que não havia em seu paciente o desejo de avançar. O sentido de continuidade necessária havia se perdido. Além disso, Minkowski (1967) acrescenta com certo destaque que o futuro do paciente estava bloqueado por este acontecimento catastrófico que lhe absorvia totalmente. Já não tinha energia para seguir a marcha da vida diária, não se detinha aos pormenores da vida nem aos temas mais fúteis, estava sempre a repetir o mesmo.

Sua pergunta inicial começava a ganhar resposta: todos nós em algum momento da vida entramos em contato com tamanho desalento e abatimento. A morte nos aparece e domina nossa imaginação bloqueando nosso futuro. Nossa experiência de sucessão do tempo vivido se esvai e acabamos por viver dias isolados e plenos de monotonia. No entanto, há em nós um impulso vital, um ímpeto pessoal que nos eleva para o futuro e faz suas portas a nós se abrirem novamente. Nossos pensamentos, obras e desejos ultrapassam essa morte que, por fim, nos atrapalhava.

Segundo Bazzo (2019), em sua compreensão acerca do termo ímpeto vital Minkowski possui influência de Bergson, para quem o conceito de elã original vital demarcava um distanciamento da compreensão mecanicista e finalista do movimento evolutivo, representando, assim, uma energia vital interior aos organismos que se direciona ao ambiente e cria novas formas de vida. Segundo a autora, Minkowski compreende ímpeto vital não mais como uma impulsão global de vida, mas como da ordem do singular, como energia afetiva que se relaciona com o ambiente, não se confundindo com a vontade ou qualquer faculdade psíquica, além disso, também está na base da construção da personalidade de cada sujeito. Minkowski também compreende que a noção de ímpeto vital e tempo não estão desvinculadas, uma vez que o ímpeto vital é a propulsão ao futuro que impulsiona cada um em direção a ele (Bazzo, 2019). 
Esse ímpeto pessoal, este impulso vital, a que tudo lhe parecia, faltava ao seu paciente. Seria possível objetar: "Não seria tal atitude a de uma pessoa condenada à morte e não estaria assim seu paciente devido a seu contexto clínico?" (Minkowski, 1967, p. 169). Sua resposta adentra uma interpretação fenomenológica acerca da mania mesma. Segue: esta pergunta pode ser feita, na verdade, pela ideia que temos sobre como um condenado à morte se sente. No entanto, tal ideia pode vir de nossa experiência e não necessariamente da realidade dessa pessoa, visto que todos nós nos damos conta ocasionalmente do fato que estamos sentenciados à morte, especialmente em momentos em que nosso impulso vital se encontra debilitado e nosso futuro encerrado. Deste modo, poderia ser possível dizer que essa vivência do paciente também pode ser consequência de um debilitar similar ao nosso, tendo acarretado em um sentimento de desintegração do tempo. Visto desta forma, afirma, a mania não é simplesmente um excesso de fantasia, senão um ramo de um fenômeno que é parte da existência de todo ser humano e que provoca fendas em nossa síntese vital.

Temos, a partir de então, a primeira correlação entre mania em sua perspectiva existencial, impulso vital $^{3} \mathrm{e}$ tempo. Minkowski (1967) segue seu texto aprofundando estes aspectos e inicia por explicar-nos o conceito de impulso pessoal. Destarte, ele procede: a crença na execução é um esforço feito racionalmente, aspecto mental conservado intacto, para estabelecer uma lógica diante de seu sofrimento. No que diz respeito ao impulso vital, ele também governa nossa relação com o mundo externo e tem, nele mesmo, elementos de expansão. Ele rebaixa os limites do ego e cria no mundo ao redor nosso cunho pessoal obras que se tornam independentes de nós e passam a existir por si só. Essa atividade, segundo o psicopatologista, contém em si um aspecto positivo chamado felicidade, um prazer que acompanha as obras acabadas e as decisões firmes.

Um sentimento radicalmente oposto à felicidade é a dor sensorial. Ela vem do exterior e a ela é intrínseco o sentimento de sofrimento, por termos de nos submeter a algo que parece ser externo. Ela evidentemente se opõe a nosso ímpeto de expansão e já não podemos mais "somarmo- nos" ao exterior, nem estampar nosso cunho pessoal nele (Minkowski, 1967). Assim, a dor também é uma reação diante do exterior, geralmente de curta duração, podendo tornar-se crônica quando não encontra a contrarreação do impulso pessoal. $\mathrm{O}$ exterior se impõe e invade a pessoa de modo que não lhe resta nada além de sofrimento. É o que Minkowski (1967) lembra seu paciente expressar: "Me lo quitarán todo menos aquello precisamente que sea necesario para hacerme sufrir" [Tirarão tudo de mim, menos precisamente aquilo que é necessário para me fazer sofrer] (Minkowski, 1967, p. 171-172). Esse era o modo como construía sua relação com o mundo, afirma seu médico. Tudo estava contra ele, tudo era violento e tudo o fazia sofrer. As coisas perderam seu caráter particular, cada um e todo mundo era visto como um universo concreto de hostilidade. Perdera a capacidade de conceber causalidades, coincidências, atos inconscientes e não intencionados na vida humana, assim como o valor corrente dos objetos.

Podemos notar que Minkowski (1967) em suas reflexões fenomenológicas lança luz às temáticas tempo, sofrimento e impulso pessoal. A temática tempo se colocou a ele de acordo com o modo como seu paciente se relacionava com o mundo, com os outros e consigo mesmo. Nesse modo, as coisas não lhe apareciam senão como acervo da política de desperdício e não lhe restava energia para ações e desejos que lhe abrissem o futuro, este se encontrando bloqueado. A questão do sofrimento se revela ao médico à medida que este se lança sobre a tarefa de compreender a oposição entre impulso pessoal e dor sensorial. O sofrimento é compreendido como sentimento inevitável diante da opressão da força externa ao organismo, causada pela dor. Força que se opõe ao movimento de expansão do impulso pessoal e bloqueia nosso sentimento de alegria que seria derivado deste último. A seguir, serão apresentadas as três temáticas de acordo com seus contextos de tratamento nas escrituras posteriores: A noção de perda de contato vital com a realidade e suas aplicações em psicopatologia (2004), Breves reflexões a respeito do sofrimento (aspecto pático da existência) (2000) e o primeiro capítulo de $O$ tempo vivido (1933/2011).

\section{AS TEMÁTICAS TEMPO, SOFRIMENTO E IMPULSO PESSOAL}

Minkowski (1967) reconhece na psicopatologia um traço da existência humana que está alterado de sua apresentação corrente e que, não obstante, nos remete ao fundo próprio do modo de ser da existência, do caráter fundamental da vida e do vivido. A seu ver, a psicopatologia é um campo de conhecimento desvelador do fenômeno psicopatológico por meio de seu caráter pathico, já distinguido por esta

3 Neste texto Minkowski utiliza o termo "impulso vital" e "ímpeto vital" como sinônimos. Nos outros textos também aparecem ambas nomenclaturas. outra ordem, a saber, a de sua relação com os aspectos fundamentais da existência (Minkowski, 2000). Em suas obras encontra-se manifesta tal concepção, facilmente percebida, de que o autor de fato se interessou antes de tudo pela própria existência do homem e seus temas fundamentais. O paciente e sua relação com o tempo suscitaram-lhe reflexões e a descoberta de que o tempo se apresentava de modo sui generis nessa relação, levando-o a compreender não apenas sua especificidade nesse caso, assim como sua especificidade na mania (Minkowski, 1967). Mas o que é o tempo? Lancemos mão aqui das reflexões de Minkowski (2011) para tal compreensão. 
A questão do tempo deve ser pensada em três diferentes aspectos: tempo da física e da memória, tempo e espaço mensuráveis e duração vivenciada. Em outras palavras, Minkowski (1967) afirma que na compreensão cotidiana de tempo, até mesmo no âmbito da física, é natural que o tempo seja assimilado, por um lado, em relação ao espaço ou, por outro, em um dinamismo extremo, tal como uma sucessão perpétua. Isso se dá porque, de algum modo, tempo e espaço devem compartilhar uma gênese. Com relação ao espaço, por exemplo, o tempo pode ser dividido em um calendário, um relógio, possuir distâncias, intervalos, ser seccionado de alguma forma. Já com relação ao dinamismo extremo, comumente é assemelhado a um caleidoscópio cujo "não cessar" peca por excesso.

Em outros escritos de Minkowski sobre o espaço é possível encontrar um aprofundamento em seu modo de compreensão deste fenômeno a partir dos estudos de Marmorato (2012). Segundo este, os conceitos de tempo e espaço estão profundamente relacionados à atividade na obra de Minkowski. A atividade, enquanto modo de relação com o espaço, entra em confluência ao movimento do ímpeto vital e abre o futuro vivendo-o de forma a organizar o tempo. Enquanto no fenômeno da espera, um modo de viver o espaço oposto ao da atividade, ainda se vivenciaria o tempo em sua forma fragmentada em uma espera de que o futuro se torne presente. Essa abertura de sentido que Marmorato (2012) adentra sobre o espaço na obra de Minkowski pode ser explorada em estudos futuros em sua relação com a tríade ímpeto vital, tempo (futuro) e sofrimento descrita no presente artigo. Pois aí há ainda possibilidades de aprofundamento da relação do homem com a atividade e sua forma de aparição em pacientes com sofrimento psicopatológico.

Retornando ao texto que aqui trazemos, o psicopatólogo menciona sobre o tempo que o caso é que nenhuma destas tentativas de explicar, compreender e analisar o tempo são compatíveis com o que o tempo é, sendo possível encontrar fenômenos temporais que fogem a estas concepções. Isso acontece porque a inteligência humana, na tentativa de explicar o fenômeno, o secciona em partes quando na verdade nós o temos em absoluto em nossa experiência. $\mathrm{O}$ tempo vivido é inacessível ao conhecimento não porque se está fora dele, mas porque se encontra completamente dado a nós e não coloca sobre sua natureza qualquer problema da ordem do pensamento (Minkowski, 2011).

Em referência a Bergson, Minkowski (2011) descreve o tempo como "massa fluida", "oceano movente" visto ao nosso redor, em mim mesmo e em todos os lugares no momento em que medito sobre o tempo. Chama a isto o devir. Nós o temos em absoluto porque ele nunca se deixa exaurir por nossos pensamentos, sentimentos e vontades. Ele nos é muito próximo, é a base de nossa vida e quase pode-se dizer que é o mesmo que ela. É universal, pessoal e caótico. Quando o definimos a partir do espaço, como o faz a física ao traçá-lo como uma linha reta, estamos na verdade expressando uma espacialização e racionalização excessivas, próprias do ser humano e não do tempo (Minkowski, 2011).

$\mathrm{Na}$ experiência de seu paciente, fica evidente para Minkowski (1967) que é sua relação com o tempo que clarifica a particularidade da psiqué. Há em todos nós uma capacidade de tirar conclusões sobre o futuro por meio dos fatos ocorrentes no presente. À medida que o enfermo insistia, dia após dia, na certeza de que aquele era o seu último dia livre das aplicações de castigos, Minkowski (1967) verificou a perda desta capacidade. Compativelmente, seus dias pareciam estar presos sempre na mesma monotonia da espera do castigo e do aumento do acervo de objetos que compunham tal desfecho. Não lhe restando nenhuma energia para direcionar suas atividades para o futuro: nenhum desejo, nenhuma ação emanava desse presente perpétuo e se lançava para o futuro. Este parecia, por fim, estar bloqueado pela certeza da catástrofe. Sua atitude geral diante do futuro estava transtornada: o tempo que para nós constitui um fenômeno integrado em um todo progressivo, para ele estava rompido em fragmentos soltos (Minkowski, 1967).

Minkowski (2004) também notou, mais tarde, esta relação característica com o tempo nos casos de esquizofrenia. A perda da mobilidade, a fixidez das coisas ao redor do mundo do esquizofrênico não the permite vislumbrar $o$ futuro. Ele descreve como sendo a perda do contato vital com a realidade acompanhada do isolamento de si, que faz com que o mundo ganhe tal imobilidade e que se chegue nesta relação com o tempo. Aprofundemos agora essa noção de contato vital da qual o autor nos fala. Neste campo de discussão, assim como falamos do tempo anteriormente, também não estamos falando das faculdades intelectuais. As faculdades do pensar, sentir, raciocinar, analisar, são apenas acontecimentos desse fundo que é o contato vital. Ele diz respeito à essência viva da pessoa em sua relação com o ambiente, diferindo-se também de um conjunto de reações ao ambiente. Não há uma separação clara entre ação e reação, fala-se mais em uma confusão, uma comunhão entre o eu e o meio. Esse ambiente não é um conjunto atômico, nem de forças, nem de energias. É sim uma "onda móvel" que nos envolve por todas as partes e aos acontecimentos que dela emergem como se fossem ilhas que vão e voltam desta onda. Eles batem nas fibras da personalidade que, penetrada pelos acontecimentos, vibram com eles em uníssono. Vibram todos de forma pessoal, por meio dos atos, "pelos risos ou pelas lágrimas" (Minkowski, 2004, p. 134) que são colocados nessa onda do ambiente, perdendo-se nele como uma gota em um oceano infinito (Minkowski, 2004).

É esse contato vital que falta no esquizofrênico, segundo o psiquiatra. Até em uma esquizofrenia avançada, pode-se encontrar as funções elementares do psiquismo intactas, sem nenhum sinal de enfraquecimento intelectual propriamente dito. No entanto, essa falta de contato vital é suficiente para que o caso seja grave. É que, tanto para compreensão do tempo, quanto para compreensão do contato vital, é preciso 
recolocar a inteligência em seu lugar para apreender tais fenômenos em sua pureza, pois a inteligência exige destes fenômenos uma determinada forma de explicar-se que não lhes cabe. Minkowski recorreu a Bergson para compreender esse tratamento à inteligência. Ele afirma que em sua noção de tempo e contato vital, o filósofo o influenciou fortemente, assim como Bleuer durante sua estada em Zurique (Minkowski, 2004).

Minkowski compreende que é desse ponto de vista do tempo vivido - anterior ao ato intelectual ou de outra ordem - que se fala quando se refere ao tempo na psicopatologia. Nessa rigidez da esquizofrenia, na falta de contato vital com a realidade, é que se apresenta também uma rigidez no tempo. As coisas e o mundo ao redor apresentamse afastados do eu como se o paciente não se sentisse pertencente ao lugar que ocupa. Há uma dissociação, um deslocamento, uma ausência entre as coisas no mundo e o eu. Por isso, as ideias do esquizofrênico são estáticas, não realizáveis: seu futuro encontra-se também bloqueado, como um eterno repetir do passado. Seu potencial criador foi abolido (Minkowski, 2004).

Essa relação entre atividade, contato vital e futuro é compreendida pelo médico como uma relação profunda e constitutiva entre os termos. Segundo ele, o ímpeto vital cria o futuro como nada mais o faz. Quando se pensa em direção no tempo, pensa-se em futuro, o futuro nos é dado de modo mais primitivo que o passado. É um impulso que nos faz progredir ao futuro. Este impulso é de modo algum passivo, ao contrário, é uma tendência espontânea do meu ser todo que me direciona ao futuro. Quando isso acontece, tudo à volta, o universo todo, progride ao futuro. Por meio de um exercício da consciência racional seria possível dizer que se descobre o ímpeto em si e ao mesmo tempo encontra-se essa direção analogamente no universo todo. No entanto, um raciocínio assim é inexato, pois segmenta os atos do ser em dois momentos distintos - ímpeto em mim e ímpeto no universo - quando há apenas um fenômeno, geral e impessoal. Em outras palavras, não há "eu progrido e o mundo também”, pois são unos. Se se pensa eu-mundo este ímpeto se divide, no entanto, ele é uno de início. Se o devir tem primeiramente aquele aspecto irracional e caótico, é apenas com o ímpeto vital que o tempo ganha sentido (Minkowski, 2011). "É o ímpeto vital que nos desvela a existência do futuro, que no-lo dá um sentido, que o abre e o cria diante de nós, esse futuro acerca do qual chegaremos a saber talvez alguma coisa" (Minkowski, 2011, p. 98).

O psiquiatra acrescenta que não se pode confundir ímpeto vital com volição ou tendência dirigida a um objeto, apesar de ele presidir o nascimento da volição ou tendência dirigida a um objeto. A despeito de ele presidir o nascimento da volição, está sempre preocupado com o "fim ou os fins pelos quais chegará a deixar qualquer coisa de concreto sobre seu caminho" (Minkowski, 2011, p. 98). Desse modo, o ímpeto vital contém nele a criação. Ele, por sua vez, cria forma no nascimento da atividade, mas é, antes, geral e indefinido.
Por isso, não se esgota em cada objeto da volição recriando o futuro diante de nós sempre que o objeto é alcançado. Em vista disso, chama-se o ímpeto vital de ímpeto para ... Um ímpeto que, contudo, não vem de algum lugar, pois a noção de que tudo que vai a uma direção (ímpeto para) vem de outra é um raciocínio que especializa e fraciona o ímpeto em partes sucessivas, quando, na verdade, ele se apresenta geral e indefinido sendo, antes, encadeado naturalmente tal como uma trama em que as partes não se diferem do todo (Minkowski, 2011).

Assim o vemos no caso estudado pelo médico. $\mathrm{O}$ impulso pessoal (ímpeto vital) e o futuro possuem uma relação determinante, já o diz Minkowski (1967). Isso acontece principalmente porque o impulso vital governa também nossa relação com nosso ambiente ao redor e com o sentido que temos dele. Se o paciente se encontrava preso no presente, não realizando o salto para o futuro, que sempre fazemos em nossas atividades, estava bloqueado devido à ausência da atividade no presente que o impulsionaria nesse avançar. Faltava-lhe o impulso pessoal (ímpeto vital). Mas o que acontece quando ele nos falta? O sofrimento, responde o médico.

O sofrimento é o acompanhante da dor sensorial que agride nosso movimento expansivo para o mundo. Nosso movimento de realização de tarefas, de finalização e criação de obras é o impulso pessoal manifesto. A capacidade de expansão que o impulso pessoal apresenta é um avanço provocado em direção ao futuro. Por meio do impulso pessoal, como dito anteriormente, as fronteiras do ego se esfumaçam e somos lançados em direção ao mundo. Por essa criação de obras e avanço no mundo é que nossa existência se realiza, carregando em si um sentimento único e de aspecto positivo chamado felicidade. Esse sentimento nos acompanha sempre no prazer da finalização de uma obra e na certeza da tomada de decisões corretas. No mundo, o que nos coloca na direção oposta a esse movimento expansivo, lutando contra ele, é a dor sensorial e o sofrimento que dela faz parte, nos descreve o psiquiatra. A dor sensorial e o sofrimento também são fatores essenciais da estrutura de nossas relações com o mundo. Se o impulso vital se realiza na expansão de nosso ser, a dor nos provoca o sentimento de que forças externas atuam sobre nós e de que a estas estamos submetidos, forçadamente entregues. De movimentos opostos, sofrimento e impulso vital comumente se chocam na existência e aquele pode tornar-se crônico, caso não encontre a resistência deste. Quando a dor e o sofrimento nos acometem, sua apresentação abafa o movimento de expansão ao mundo do impulso pessoal, impedindo-nos a nossa existência em soma com o mundo e perdurando o sentimento de que nada mais pode ser feito a não ser deixarse ser invadido e sofrer (Minkowski, 1967). Relembro as palavras de seu paciente: "Me lo quitarán todo menos aquello precisamente que sea necesario para hacerme sufrir" [Tirarão tudo de mim, menos precisamente aquilo que é necessário para me fazer sofrer] (Minkowski, 1967, p. 171-172). O 
sofrimento constitui as relações do paciente com o exterior. É ele que tonaliza o modo como as coisas lhe aparecem, assim como as pessoas. Ele faz parte de seu existir de um modo muito profundo. De que ele (o sofrimento) nos fala ao mostrar-se em tal profundidade?

O sofrimento é parte da existência. No entanto, ele não está para ela como as outras partes. Ele a posiciona: é um pedido da própria vida nos chamando a nos reaver com a existência. Mostra-se, assim, no domínio do pathos humano. Ele simplesmente está aí e nos faz sofrer, não se colocam questões sobre se deve ser evitado, aceito, buscado, se é positivo ou negativo. É reconhecido usualmente como vindo do exterior, mas esta não é sua única origem. Não há quem não o tenha passado na vida e não o tenha encontrado (Minkowski, 2000). Diz-se de quem dele tenha sido poupado que "no fundo seria dizer que não soube sofrer. E isso seria grave para ele" (Minkowski, 2000). Ele não tem sentido em si, mas coloca ao homem a questão do sentido da vida: o homem o conhece pelos problemas da existência. Quando isso acontece, ele se integra ao dinamismo da vida e reagimos com abatimentos e desesperanças. Ele não é esquecido (o tempo cura), é integrado naturalmente no mundo da vida, provoca-nos imobilidade, rigidez, desorientação e o sentimento de estar preso. Isso pode-se verificar nas pessoas que insistem em mostrar "sua face lacrimosa" ao mundo. O encontro com o sofrimento do outro nos mobiliza compaixão e vamos ao socorro daquele que sofre. No entanto, sempre nos fica a fenda de uma "outra coisa" necessária. A nós só nos resta dar conselhos e essa "outra coisa" parece necessitar de que o sofredor a desenrole a sós, em um debate consigo mesmo (Minkowski, 2000).
Segundo Minkowski (2000), a fixidez produzida pelo sofrimento é falha, produz dor profunda e solicita debate consigo mesmo. Transforma, nestes mesmos passos, nossa relação com o mundo e nos faz entrar em um acordo discordante com ele. É um desacordo porque minha face voltada ao mundo pode ser vista como positiva. Esta face é meu pessoal-social, minhas relações sociais comuns e vivas. Em contrapartida, é um acordo porque esta mesma face se alimenta do padecer do sofrimento que carrega em si. Diante desse apelo da existência, não há um esforço propriamente dito que se fala em direção às suas vicissitudes inevitáveis. É preciso coragem, mas isto não é o estado das coisas. A reação acontece sozinha, vem do próprio dinamismo da vida, fundador da existência (Minkowski, 2000). Em sua apresentação mais rotineira e, no entanto, mais elementar, o sofrimento coloca-nos diante da angústia. Fenômeno pathico em sua constituição, a angústia não é patológica em sua natureza. É preciso compreendê-la desde então, no domínio do patológico. Ela se encontra em todas as reviravoltas da existência e sob as mais diversas formas do homem:

Para o homem, a vida é uma estrada a ser percorrida e essa estrada não tem em si nada de metafórico. No fundo é a única estrada que eu devo necessariamente percorrer na vida, traçando-a e construindo-a inteiramente com minhas mãos. Naturalmente falaremos agora de reviravoltas em nossa estrada, se bem que nessa estrada entenda-se reta diante de nós, ou ainda, de seguir a estrada certa, se bem que a estrada, por ser estrada humana, não possa ser senão a estrada certa. (Minkowski, 2000, p. 161)

\section{CONSIDERAÇÕES FINAIS}

O autor debruçou-se sobre o fenômeno psicopatológico em suas dimensões existenciais refletindo e afinando questões sobre o sofrimento em suas facetas cotidianas - a nostalgia, a ansiedade e a angústia; o tempo vivido, o passado, o presente, o futuro e a duração. Pôde-se compreender que o sofrimento na existência revelou ao médico o fenômeno do tempo e do ímpeto vital em seus aspectos fundamentais à vida humana. Minkowski (2011) expressa que o ímpeto vital, a força criadora, abre o tempo vivido e desloca nosso ser ao futuro. Sem ímpeto vital não há futuro, há tempo fragmentado, estagnado e assim o é o ser que dessa forma se relaciona com o tempo. Ou há a perda do contato vital com a realidade (como na esquizofrenia) ou há uma relação monótona e rígida com o mundo (como no caso estudado) que revelam esta fragmentação e estagnação de si na camada cotidiana da vida. Acontece que nesta camada, a falta do poder criador que nos impulsiona ao futuro, a falta do ímpeto vital como força expansiva que age no mundo deixa aparecer esta outra força no sentido oposto, sentido invasor, sentido daquilo que nos acomete e parece não nos deixar saída - que é o sentido do sofrimento, com seu caráter pathico. A tríade ímpeto vital, futuro e sofrimento formam esta trama relacional importante de ser considerada no estudo da existência e, assim, da psicopatologia. E foi especialmente em direção aos matizes dessa trama que este estudo buscou chamar a atenção.

Em uma época em que se apresentam tantos dados sobre o aumento alarmante dos números de diagnósticos de depressão e ansiedade, por exemplo, a retomada dos estudos de Minkowski não apenas aprofunda e fornece um novo o olhar à existência humana, como também nos faz saltar aos olhos a tensão que existe entre as exigências do mundo e o tempo vivido mais próprio de nosso ser, tal como experimentados no pathos vivido na depressão e na ansiedade.

Em outras palavras, aproximar-se da noção de tempo mais fundamental sobre a qual Minkowski se debruça pode auxiliar-nos em possíveis reflexões sobre o mundo que habitamos e quais as possibilidades de ser que aí se apresentam, contribuindo para o seu adoecimento. Trabalhos futuros que aprofundem a compreensão de tempo, 
ímpeto vital e sofrimento podem facilitar a apropriação da compreensão da psicopatologia a partir dos elementos já sempre imbricados ao próprio movimento de existir, abrindo novas perspectivas para a clínica psicológica e psiquiátrica menos tecnicista e mais vinculada ao movimento da vida e, portanto, mais humana.

\section{REFERÊNCIAS}

Abreu e Silva Neto, N. (2004). A atualidade da obra de Eugène Minkowski (1885-1972). Boletim da Academia Paulista de Psicologia, XXIV (2). http://www.redalyc.org/articulo. oa? id $=94612361010$

Antúnez, A. E. A., Gonzales, L., \& Faizibaioff, D. S. (2014). O tempo vivido no acompanhamento terapêutico. Revista Atravessar, 4, 5-24. https://pt.scribd.com/document/362168113/RevistaATRAVESSAR-de-Acompanhamento-Terapeutico-04-2014

Antúnez, A. E. A., \&Faizibaioff, D. S. (2014). Sobre o aspecto temporal da vida em Minkowski: Revisando o Tempo Vivido. Psicopatologia Fenomenológica Contemporânea,3, 48-115. https://doi.org/10.37067/rpfc.v3i1.1016

Barthélémy, J.-M. (2015). Princípios fundadores e atualidade de uma prática psicoterapêutica de orientação fenômeno-estrutural Revista da Abordagem Gestáltica, 21(2), 143-149.http:// pepsic.bvsalud.org/scielo.php?script=sci arttext\&pid=S180968672015000200004\&lng $=$ pt\&tlng $=\mathrm{pt}$

Bazzo, R. (2019). Eugène Minkowski - Estudo psicológico e análise fenomenológica de um caso de melancolia esquizofrênica. Psicopatologia Fenomenológica Contemporânea. 8(1), 6492. https://www.revistapfc.com.br/rpfc/article/view/959/959

Bloc, L., Souza, C., \& Moreira, V. (2016). Phenomenology of depression: Contributions of Minkowski, Binswanger, Tellenbach and Tatossian. Estudos de Psicologia (Campinas), 33(1), 107-116.https://www.scielo.br/pdf/estpsi/v33n1/0103166X-estpsi-33-01-00107.pdf

Costa, V. E. S. M., \& Medeiros, M. (2009). O tempo vivido na perspectiva fenomenológica de Eugène Minkowski. Psicologia em Estudo, 14(2), 375-383. http://www.scielo.br/pdf/pe/v14n2/ v14n2a18.pdf

Denischik, M. (2015). Temporality in psychosis: Loss of lived time in an alien world. The Humanist Psychologist, 43, 148-159. https://www.apa.org/pubs/journals/features/hum-43-148.pdf

Feijoo, A. M. L. C., \& Mattar, C. M. (2016). Encontros e desencontros nas perspectivas existenciais em psicologia. Psicologia em Revista, 22(2), 258-274. 10.5752/P.1678-9523.2016V22N2P258

Marmorato, P. G. (2012). A hiperatividade no tempo de Minkowski. Psicologia Fenomenológica Contemporânea. 1(1), 23-13. https://www.revistapfc.com.br/rpfc/article/view/1045/1045
Minkowski, E. (1967). Hallazgos en un caso de depresión esquizofrénica. In R. May, E. Angel, \& H. F. Ellenberger (Orgs.). Existencia: Nueva dimensión en psiquiatría y psicología (C. S. Gil, Trad., pp. 163-176). Editora Gredos, S.A. (Obra original publicada em 1958)

Minkowski, E. (2000). Breves reflexões a respeito do sofrimento (aspecto pático da existência). Revista Latinoamericana de Psicopatologia Fundamental,III(4), 156-164. http://www. redalyc.org/articulo.oa?id $=233017663011$

Minkowski, E. (2004). A noção de perda de contato vital com a realidade e suas aplicações em psicopatologia. Revista Latinoamericana de Psicopatologia Fundamental, VII(2), 130146. http://www.redalyc.org/articulo.oa?id=233017780008

Minkowski, E. (2011). O tempo vivido. Revista da Abordagem Gestáltica,XVII(1), 87-100. http://pepsic.bvsalud.org/pdf/rag/ v17n1/v17n1a12.pdf

Minkowski, E. (2016). O delírio. Psicologia Fenomenológica Contemporânea, 5(1), 72-85. https://www.revistapfc.com.br/ $\mathrm{rpfc} /$ article/view/989/989

Pereira, M. E. C. (2000). Minkowski ou a psicopatologia como psicologia do pathos humano.Revista Latinoamericana de Psicopatologia Fundamental,3, 153-155. https://doi. org/10.1590/1415-47142000004011

Pienkos, E. (2015). Intersubjectivity and its role in schizophrenic experience. The Humanist Psychologist, 43, 194-209.https:// www.apa.org/pubs/journals/features/hum-43-194.pdf

Souza, C., Melo, A. K., \& Moreira, V. (2020). The lived space of Ana: A clinical case study from the perspective of phenomenological psychopathology. Trends in Psychology,28, 16-30. 10.9788/s43076-019-00010-5

Souza, C., \& Moreira, V. (2018). A compreensão da experiência de depressividade na tradição da psicopatologia fenomenológica. Psicologia: Teoria e Pesquisa, 34, e3447. $10.1590 / 0102.3772 \mathrm{e} 3447$

Urfer, A. (2001). Phenomenology and psychopathology of schizophrenia: the view of Eugène Minkowski. Philosophy, Psychiatry, \& Psychology,8(4), 279-289. 10.1353/ ppp.2002.0029 